\title{
On the nature of reality
}

\author{
Boxed in.
}

“This looks wrong," Detective Hawthorne mumbled. The interior of the bedroom felt dark, but not because of the ambience - the old ornate chandelier would've been enough to illuminate two such rooms. Something strange was eating the light: little black cubes, each one about the size of a palm. They covered the floor and rose in heaps against the walls like badly digitized termite mounds; a jungle as Picasso might have imagined it. There were clearings on the bed, where Dr Mayerhofer must've been sleeping, and on the desk. A window stood open, and a curtain waved in the wind with a rustle that sounded as though someone was whispering a poem.

On the desk lay a tablet and a small brown box. The box was a piece of science, the tablet was evidence; the latter naturally came first. Hawthorne tapped the screen and studied the text Mayerhofer seemed to have been working on before the fatal incident.

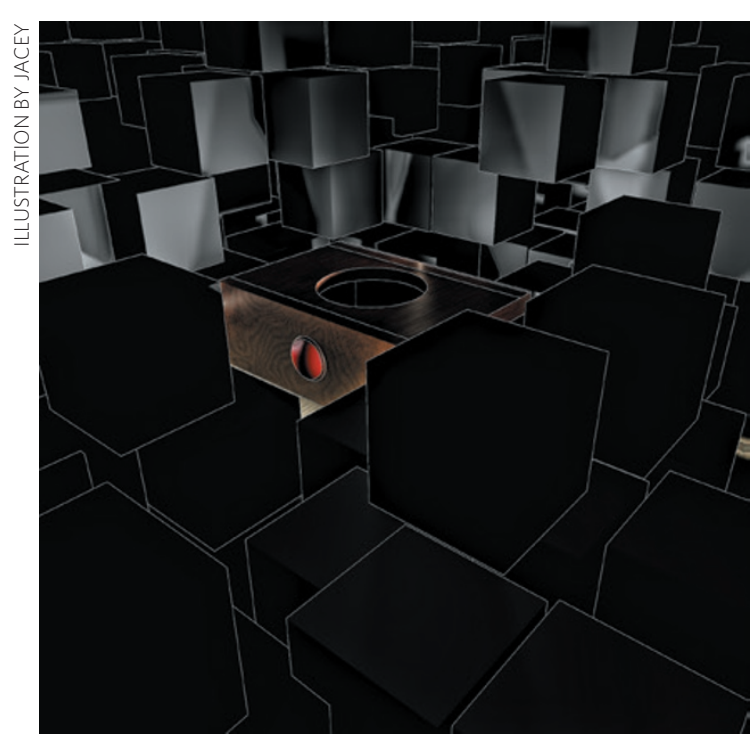

17.04.2016 The thing turned out to be a hoax. I pressed the button, a long pause followed, and the device spewed out a tiny black cube which immediately fell on the floor and bounced under the table. Had to search for it for a solid ten minutes. Nonsense. Must be an April Fool's joke - today is the 17th, but we all know how the Post Office works.

18.04.2016 Forgot to dispose of the box in the morning and, when I came back from work, there were two more cubes next to the one from yesterday. The cleaning lady must've accidentally pressed the button - or maybe she was curious. I did the measurements: the cubes are exactly four inches wide, and the device is six by five by five. No way three of those little buggers could fit inside.

19.04.2016 I was late for work today, spent the whole morning fiddling with the box. There are a hundred and ten cubes on my desk now, all identical in size and shape. I could try to disassemble the device, but I can't risk breaking it.

21.04.2016 Had a eureka moment this evening. The box doesn't weigh much, so the material for the cubes must come from the outside - the air or even light itself. Good old Sherlock: when you have eliminated the impossible, whatever remains must be the truth. The device is of a quantum nature, performing a physical transformation of matter. The biggest breakthrough since stopping the photon! Spilled my tea while thinking about this, because my hands are trembling - with excitement, needless to say. I'm not the inventor, but I was the first to experiment with the device. And no one excludes the possibility of a couple of joint papers. Science perhaps, or Nature? I will take the

17.04.2016 The postman delivered a parcel today. No name on it, just the return address: a place somewhere in China. Inside, there's a postcard and a box. The postcard: yellowish, grainy surface, a picture in fading colours of the gateway to the Ming Tombs. Otherwise blank. The $\rightarrow$ NATURE.COM

Follow Futures: y @NatureFutures f go.nature.com/ mtoodm

\section{box: a red button,} an orifice, but apart controls, indicators or panels. Smart. from that - no other

5 minutes: two dozen cubes - they kept coming out with the same periodicity. I do not understand. I do not understand.

25.04.2016 It's been three days. Took a vacation and did what I should've done from the start: disassembled the box. The fear of breaking it was futile; inside, there's only a battery and a microchip. Once you push the button, the cube appears ... How can I describe it? Like something is in your blind spot, but then you turn your head, and the object is suddenly there. Oh God oh God oh my God. The only good thing is, it took nothing to put the device back together.

27.04.2016 Of course, the possibility always remains of alternate dimensions, green aliens or divine intervention ... Right now, I sorely wish I believed any of these. But I don't; the cubes do not exist. They come out of nothing, so they are nothing. And yet they seem so real I can cut my hand with them. I can cut it, there's blood.

30.04.2016 Science works by generalization; my desk consists of atoms, the same quarks and electrons as the cubes - by extension, it doesn't exist either. Nor do the walls, the floor, the ceiling.

04.05.2016 I now understand why the postcard was empty, and there was no name on the parcel. The Chinese inventor must've arrived at the same conclusions as I did. Names don't matter. Thoughts don't matter. Speech doesn't matter. They say consciousness is an emergent property of the brain, but how can something emerge from nothing? There's no brain no neurons there's no me no me no me.

10.05.2016 We're not air, we're not even light; we're contours outlining nothing.

The text ended there. Hawthorne looked at the open window and tried to imagine Dr Mayerhofer's final thoughts before the jump. Was he desperate? Or dispassionate? There were a few thousand cubes in the bedroom; prior to his demise, the professor must've been continuously pushing the button for at least a day.

Hawthorne's gaze shifted to the device, observing it for a minute. Moving as if in a dream, his thumb held down the red button; after ten or fifteen seconds, a black cube rolled out of the orifice and knocked against the heap of its lookalikes. The detective paused, examining the box.

Then he pressed the button again.

\section{YAROSLAV BARSUKOV is a Russian} software engineer and science-fiction writer currently living in Vienna, Austria. He was mathematics and computer science. born in Moscow and has degrees in applied 